\title{
Assessment of hearing loss among taxi and agency drivers in a city in northern Iran in 2011
}

\author{
Beheshti MH, $\mathrm{MSc}^{1}$, Firoozi chahak A, MSc ${ }^{1}$, Alinaghi Langari AA, $\mathrm{MSc}^{2}$ \\ 1- Faculty Member, Dept. of Occupational Health, Faculty of Health, Gonabad University of Medical Sciences, Gonabad, Iran. 2- \\ Faculty Member, Dept. of Occupational Health, Faculty of Health, Bam University of Medical Sciences, Bam, Iran.
}

\begin{abstract}
Received: January 2016, Accepted: April 2016

Background: Taxi drivers have the most important role in the public transport services. They are exposed to various harmful agents and occupational hazards. Noise is a harmful occupational factors and hearing loss is its most important effect. Protection of drivers against hearing loss is essential. This study was performed to determine the prevalence of hearing loss among taxi and agency drivers.

Materials and Methods: This cross-sectional study was performed on 95 drivers (43 taxi drivers and 52 agency drivers) who were selected via simple random sampling. The threshold of drivers' hearing was measured by an audiometer. After data extraction, data were analyzed using Kruskal-Wallis test to compare the average level of hearing between the left and right ears and drivers.

Results: The average age of taxi drivers and agency drivers was $43.5 \pm 10.8$ and $40.7 \pm 8.3$ years, respectively. In addition, the average work experience of taxi drivers and agency drivers was 9.5 and 6.5 years, respectively. The average of hearing threshold level in right and left ears of agency drivers was $12.96 \pm 4.2$ and $12.74 \pm 4.64 \mathrm{~dB}$ and of taxi drivers was $12.53 \pm 5.16$ and $15.61 \pm 12.7 \mathrm{~dB}$, respectively. A hearing threshold of less than $25 \mathrm{~dB}$ in each ear illustrates the lack of hearing loss; thus, the studied drivers did not have hearing loss.

Conclusions: The results showed that the drivers hearing status was satisfactory. Furthermore, the prevalence of hearing loss in taxi drivers was higher than agency drivers.
\end{abstract}

Keywords: Hearing Loss, Noise-Induced Hearing Loss, Noise, Drivers, Audiometry.

\section{Introduction}

Noise is irregular and unwanted sound waves that generally exposure to them is inevitable (1). Noise is one of the factors threatening the health of workers in different occupations such as taxi driving. Sound can have significant effects on humans from different aspects. In addition, it can lead to hearing impairments and physiological effects such as increased blood pressure and heart rate, impact on visual organs and the human balance control system, psychiatric and neurological effects, sleep disorders, subjective effects, interference in communication, and social problems (2-8). Noise in the work environment can affect individuals' safety and efficacy, and thus, may lead to accidents in the workplace. Communication problems, failure to maintain alertness and concentration, and stress and fatigue increase in individuals who are exposed to noise (9-12). Hearing loss is the most important noise-induced disorder, although noise-induced hearing loss is preventable. However, it is now considered as a major health problem and one of the 10 most common occupational diseases, and thus, as one of the most important occupational diseases in Europe $(13,14)$. The World Health Organization (WHO) has estimated the daily amount of financial losses caused by noise as nearly 4 million dollars

\footnotetext{
Corresponding author: Ali Firoozi chahak, Dept. of Occupational Health, Faculty of Health, Gonabad University of Medical Sciences, Gonabad, Iran. Email: ali_firoozi66@yahoo.com
} 
(15).In 1992, it was estimated that approximately 1.7 million people in the UK were experiencing hearing loss (16). According to the WHO, noise pollution is considered as the third harmful factor in large cities. Although noise pollution in urban areas is caused by a variety of sources such as road traffic, construction, businesses, airports, and industrial and residential areas (7, 17), vehicle traffic is the most important factor in the development of urban noise (18). This problem is intensified by the increase in vehicles in urban networks (19). Automobiles are considered as moving environmental sources of noise (traffic) and also occupational sources of noise for drivers (17). Driving is one of the occupations that expose individuals to physical and psychological stressors such as noise, vibration, oscillation, and ergonomic problems and safety risks such as accidents $(20,21)$. Drivers are exposed to high levels of noise due to working with old and faulty vehicles, on very bumpy roads, and dealing with different people during their work shift (22).Many studies have been conducted in industrial environments in relation to occupational hearing loss; however, very few studies have been performed on hearing loss in taxi drivers. The study conducted by Lewis et al. on drivers showed that the threshold of hearing in $22 \%$ of drivers was high at frequencies ranging from 3000 to $6000 \mathrm{~Hz}$ and its value increased with age (23). Berjis et al. in their study on drivers of heavy vehicles, showed that hearing thresholds at $2000 \mathrm{~Hz}$ in the left ears of subjects were significantly higher than the right ears (24). In many studies, the prevalence of hearing loss among drivers has been reported as $32.6 \%$ to $55.4 \%(25,26)$. This study aimed to determine the prevalence of hearing loss among taxi drivers in a city in northern Iran.

\section{Material and Methods}

In this cross-sectional study that was conducted in 2011, the hearing of 95 drivers in a northern city of Iran was evaluated. The participants were divided into two groups of taxi drivers $(n=43)$ and agency drivers $(\mathrm{n}=52)$. The number of subjects was determined according to the formula for determination of sample size in descriptive studies (Equation 1).

$$
\mathbf{n}_{0}=\frac{z_{1-\frac{\alpha}{2}}^{2} * \mathbf{p q}}{\mathbf{d}^{2}} \quad \text { Equation } 1
$$

The subjects were selected randomly. The inclusion and exclusion criteria of this study consisted of 1 year work experience, lack of neurological and hearing disorders, willingness to participate in the study, and lack of a second job.

It should be noted that confounding factors, such as history of ear disease, history of working in noisy work environments and risk of hearing loss caused by it, use of certain drugs such as streptomycin and gentamicin, a blow to the head, and etcetera that affect the hearing, were excluded from the study. After recording the demographic data of drivers, an audiometer (MAICO, Minneapolis, MN, USA) was used to assess the status of their hearing. The audiometry test was performed in an acoustic room. The hearing thresholds of drivers were measured separately for left and right ears at frequencies of 250, 500, 1000, 2000, 4000, and $8000 \mathrm{~Hz}$ and were recorded on audiogram sheets. In the next step, the average of the hearing thresholds was calculated per person at frequencies of 500 to $4000 \mathrm{~Hz}$ for each ear. In this study, all data were analyzed in SPSS software (version 17, SPSS Inc., Chicago, IL, USA). In addition, KruskalWallis test was used to compare the average level of hearing between left and right ears and drivers.

\section{Results}

The demographic information of these subjects is presented in tables 1 and 2. Mean age of all drivers was $41.9 \pm 9.6$. Mean age of taxi and agency drivers was $43.5 \pm 10.8$ and $40.7 \pm 8.3$, respectively. 
Table 1: The age range of studied taxi and agency drivers $(n=95)$

\begin{tabular}{ccc}
\hline \multirow{2}{*}{ Age group } & Taxi drivers & Agency drivers \\
\cline { 2 - 3 } Less than 30 years & Number $(\%)$ & Number $(\%)$ \\
\hline 30 to 40 years & $5(11.6)$ & $6(11.5)$ \\
\hline 40 to 50 years & $10(23.3)$ & $13(25)$ \\
\hline More than 50 years & $12(37.2)$ & $26(50)$ \\
\hline
\end{tabular}

According to the results of this study, mean work experience of drivers was $7.9 \pm 3.4$ years, and maximum and minimum work experience of drivers was 22 years and 1 year, respectively. The range of work experience of the studied taxi and agency drivers is shown in table 2.

Table 2: The work experience range of the studied taxi and agency drivers

\begin{tabular}{ccc}
\hline \multirow{2}{*}{ Work experience (years) } & Agency drivers & Taxi drivers \\
\cline { 2 - 3 } & Number (\%) & Number (\%) \\
\hline Less than 5 & $22(42.3)$ & $17(39.5)$ \\
\hline 5 to 10 & $19(36.5)$ & $3(7)$ \\
\hline 10 to 15 & $4(7.7)$ & $1(2.3)$ \\
\hline 15 to 20 & $3(5.8)$ & $8(18.6)$
\end{tabular}

Mean hearing threshold level (at 500 to 4000 $\mathrm{Hz}$ ) for right and left ears of agency drivers was $12.96 \pm 4.2$ and $12.74 \pm 4.64 \mathrm{~dB}$ and taxi drivers was $12.53 \pm 5.16$ and $15.61 \pm 12.7 \mathrm{~dB}$, respectively. Mean hearing loss in the two groups of drivers, according to sound-frequency, is shown in table 3 and figure 1.

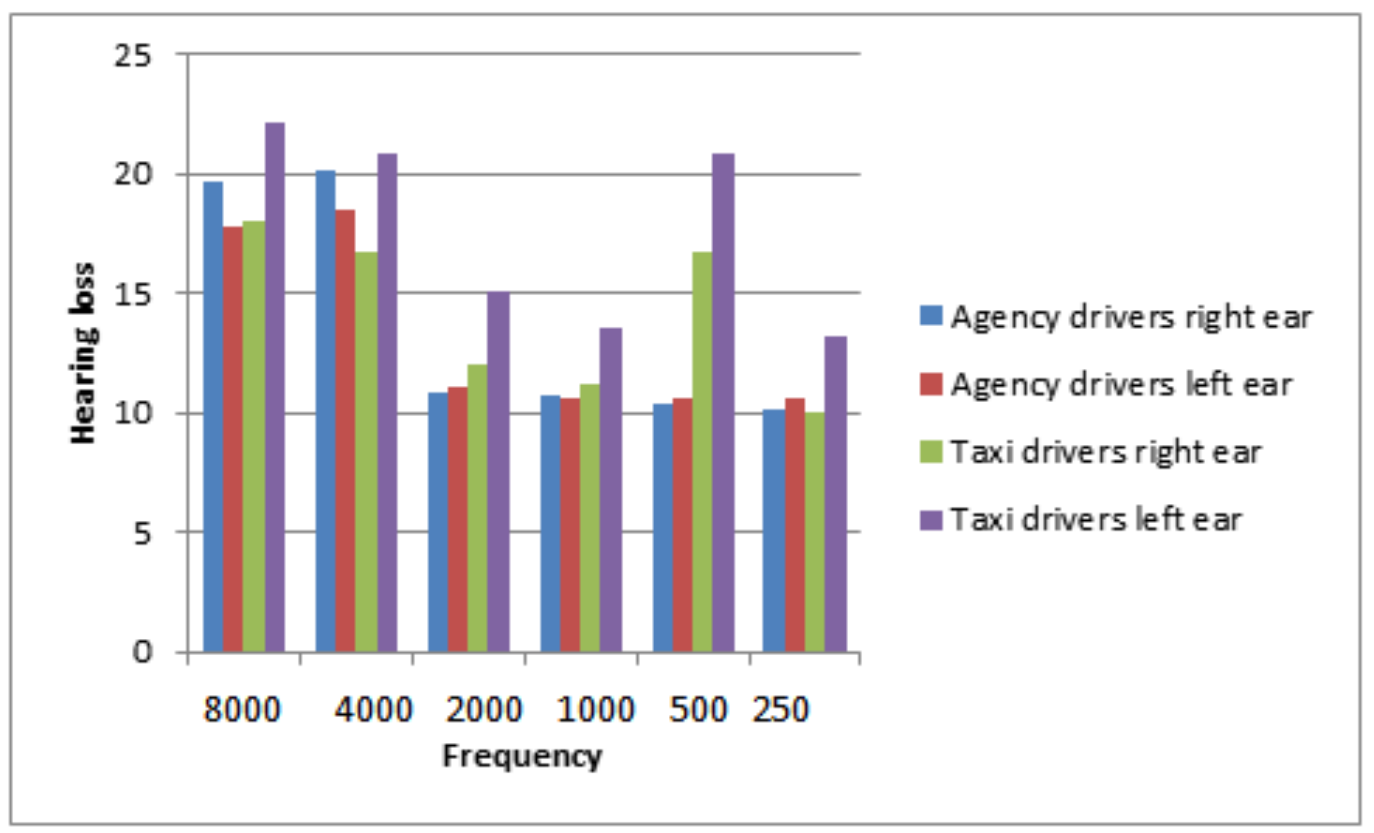

Figure 1: Mean hearing loss according to sound-frequency among taxi and agency drivers 
Table 3: Overall hearing loss in taxi and agency drivers

\begin{tabular}{cccc}
\hline Group & Ear & Hearing loss & Overall hearing loss \\
\hline \multirow{2}{*}{ Agency drivers } & Right & $12.96 \pm 4.4$ & \multirow{2}{*}{$13.42 \pm 4.2$} \\
\cline { 2 - 3 } & Left & $12.74 \pm 4.64$ & \multirow{2}{*}{$14.6 \pm 8.17$} \\
\cline { 2 - 3 } Taxi drivers & Right & $12.53 \pm 5.16$ & \\
\cline { 2 - 3 } & Left & $15.61 \pm 12.7$ & \\
\hline
\end{tabular}

In this study, $77.5 \%$ of agency drivers and $6.98 \%$ of taxi drivers had partial hearing loss. Overall hearing loss in taxi and agency drivers is shown in table 3.

According to table 3 , the incidence of hearing loss was higher in taxi drivers than agency drivers. Kruskal-Wallis test results showed no significant difference between the two groups in terms of hearing loss $(\mathrm{P}>0.050)$. Spearman's correlation coefficient showed that in agency drivers and taxi drivers there was a significant relationship between hearing loss and age with correlation coefficients of 0.497 and 0.666 , respectively, $(\mathrm{P}<0.001)$. There was a significant correlation $(\mathrm{r}=0.485)$ between hearing loss and work experience in taxi drivers $(\mathrm{P}<0.001)$. However, no significant correlation was observed between hearing loss and work experience in agency drivers $(\mathrm{P}>0.050)$. According to the Kruskal-Wallis test results, there was no significant difference in the mean threshold of hearing of right and left ears between the two groups $\left(\mathrm{P}_{\text {left }}=0.920\right)\left(\mathrm{P}_{\text {right }}=\right.$ $0.280)$.

\section{Discussion}

The results of this study indicated that the drivers' hearing status was satisfactory. This may be due to lack of traffic on roads and streets and lack of noise-producing resources in their city. The low work experience of drivers may also be the cause of this result. The study by Pourabdian et al. showed that the prevalence of bilateral noise-induced hearing loss in drivers in Isfahan, Iran, was $18.1 \%$ (27). The prevalence rates were higher in the left ear $(6.5 \%)$ than the right ear (3.0\%) (27).
The results of the present study showed that hearing loss or, in other words, average hearing threshold level in taxi drivers was higher than agency drivers. One reason for this could be that taxi drivers drive throughout their work shift and circulate in the streets. Nevertheless, agency drivers only drive and are exposed to noise when they have passengers and stop at the agency when they do not. As shown in many studies, average of hearing threshold at $4000 \mathrm{~Hz}$ in the left and right ear of drivers is greater than other frequencies, which confirms occupational hearing loss $(28,29)$.

The results of this study show that the hearing threshold of agency drivers in the right ear was higher than the left ear. This finding is not in agreement with the results of the study by Berjis et al. (24). Lopes et al. in their study showed that hearing loss is significantly associated with age and work experience of drivers (23), which is in contradiction with the results of this study. Many studies $(30,31)$ have shown that hearing loss affects health and quality of life (QOL) and the prevalence of hearing loss may be growing because of an aging population and increasing noise exposure. The study by Agrawal showed that in 2003-2004, 16.1\% of US adults (29 million Americans) had voice frequency hearing loss (30). In the youngest age group (20-29 years), $8.5 \%$ exhibited hearing loss, and the prevalence seemed to be growing among this age group. The odds of hearing loss were 5.5 times higher in men compared to women and $70 \%$ lower in black subjects compared to white subjects. Increases in hearing loss prevalence occurred earlier among participants who smoked, were exposed to noise and at risk of 
cardiovascular diseases (30). The study by Shargorodsky also showed that the prevalence of any hearing loss in adolescents in the US increased significantly from $14.9 \%$ in $1988-1994$ to $19.5 \%$ in $2005-2006$ (31). Thus, the prevalence of hearing loss among a sample of adolescents in the US aged 12 to 19 years was higher in 2005-2006 compared with 1988-1994 (31).

Effective factors in differentiating between the results of studies are driving type (urban or suburban) and vehicle type (light or heavy vehicle). Other effective factors in desirability of Hearing status of drivers investigated in this study can be their work experience, because work experience of $42.2 \%$ of agency drivers and $39.5 \%$ of taxi drivers was less than 5 years that included more than a third of the drivers. However, based on the results of this study, taxi drivers did not have noise-induced hearing loss. Nevertheless, human exposure to noise can lead to effects and complications such as temporary and permanent hearing loss, neurological and psychiatric disorders, reduced efficiency, and increased hazards $(32,33)$. Furthermore, noise has indirect effects on human performance including efficiency and productivity reduction, and increased risk of accidents due to lower focus (34). Therefore, you must first apply the sound control on the devices that produce a lot of noise.

\section{Conclusion}

According to results of this study, the average of hearing threshold level in right and left ears of agency drivers was less than $25 \mathrm{~dB}$ and the studied drivers did not have hearing loss.

\section{Acknowledge}

We would like to thank the drivers who participated in this project and helped us in performing this project.
Conflict of interests: None declared.

\section{References}

1. Golmohammadi R. Noise and vibration engineering. $3^{\text {rd }}$ ed. Hamadan: Daneshjo Press; 2007.

2. Ali SA, Tamura A. Road traffic noise levels, restrictions and annoyance in Greater Cairo, Egypt. Appl Acoust 2003; 64(8):815-23.

3. Altura BM, Altura BT, Gebrewold A, Ising H, Gunther T. Noise-induced hypertension and magnesium in rats: relationship to microcirculation and calcium. J Appl Physiol 1992; 72(1):194-202.

4. Berrien FK. The effects of noise. Psychol Bull 1946; 43(2):141-61.

5. Cheung CK. Organizational influence on working people's occupational noise protection in Hong Kong. J Safety Res 2004; 35(4):465-75.

6. Hiller W, Goebel G. A psychometric study of complaints in chronic tinnitus. $\mathbf{J}$ Psychosom Res 1992; 36(4):337-48.

7. Stansfeld SA, Sharp DS, Gallacher J, Babisch W. Road traffic noise, noise sensitivity and psychological disorder. Psychol Med 1993; 23(4):977-85.

8. Talbott EO, Gibson LB, Burks A, Engberg $\mathrm{R}$, McHugh KP. Evidence for a doseresponse relationship between occupational noise and blood pressure. Arch Environ Health 1999; 54(2):71-8.

9. da Silva GLL, Goffi Gomez MVS, Zaher VL. Audiological profile of ambulance drivers of two hospitals in the city of São Paulo-Brazil. Int Arch Otorhinolaryngol 2006; 10(2):132-40.

10. Hétu R, Quoc HT. Psychoacoustic performance in workers with PAIR. In: Axelsson A, Borchgrevink H, Hamernik RP, Hellstrom P, Henderson D, Salvi RJ, editors. Scientific basis of noise-induced hearing loss. New York: Thieme; 1996. P.264-85.

11. Picard M, Girard SA, Simard M, Larocque R, Leroux T, Turcotte F. Association of work-related accidents with noise exposure in the workplace and noise-induced hearing loss based on the experience of some 240,000 person-years of observation. Accid Anal Prev 2008; 40(5):1644-52.

12. Reilly MJ, Rosenman KD, Kalinowski DJ. Occupational noise-induced hearing loss 
surveillance in Michigan. J Occup Environ Med 1998; 40(8):667-74.

13. Monson RR. Occupational epidemiology. $2^{\text {nd }}$ ed. Boca Raton, FL: CRC Press; 1990.

14. Sulkowski W, Szymczak W, Kowalska S, Sward-Matyja M. Epidemiology of occupational noise-induced hearing loss (ONIHL) in Poland. Otolaryngol Pol 2004; 58(1):233-6.

15. Ahmed HO, Dennis JH, Badran O, Ismail M, Ballal SG, Ashoor A, et al. Occupational noise exposure and hearing loss of workers in two plants in eastern Saudi Arabia. Ann Occup Hyg 2001; 45(5):371-80.

16. Godlee F. Noise: breaking the silence. BMJ 1992; 304(6819):110-3.

17. Maleki K, Hosseini SM, Nasiri P. The effect of pure and mixed plantations of robinia pseudoacasia and pinus eldarica on traffic noise decrease. International Journal of Environmental Sciences 2010; 1(2):213-24.

18. Soh KB. Noise is a public health and social problem in Singapore .Singapore Med J 1999; 40(9):561-2.

19. Ouis D. Annoyance from road traffic noise: a review. J Environ Psychol 2001; 21(1):101-20.

20. Guidotti TL, Cottle MK. Occupational health problems among transit workers. Public Health Rev 1987; 15(1-2):29-44.

21. Rydstedt LW, Johansson G, Evans GW. The human side of the road: improving the working conditions of urban bus drivers. $\mathrm{J}$ Occup Health Psychol 1998; 3(2):161-71.

22. Mukherjee AK, Bhattacharya SK, Ahmed S, Roy SK, Roychowdhury A, Sen S. Exposure of drivers and conductors to noise, heat, dust and volatile organic compounds in the state transport special buses of Kolkata city. Transp Res D Transp Environ 2003; 8(1):119.

23. Lopes AC, Otowiz VG, Lopes PM, Lauris JR, Santos CC. Prevalence of noise-induced hearing loss in drivers. Int Arch Otorhinolaryngol 2012; 16(4):509-14.

24. Berjis N, Soheilipoor S, Poorabdian S, Akbari S. Evaluating the Relative Frequency or Hearing Loss on Heavy Vehicles Derivers. Journal of Isfahan Medical School 2011; 28(120):1-6.

25. Santos AS, Castro Júnior Nd. Brainstem evoked response in bus drivers with noiseinduced hearing loss. Braz J Otorhinolaryngol 2009; 75(5):753-9.

26. Barbosa AS, Cardoso MR. Hearing loss among workers exposed to road traffic noise in the city of São Paulo in Brazil. Auris Nasus Larynx 2005; 32(1):17-21.

27. Janghorbani M, Sheikhi A, Pourabdian S. The prevalence and correlates of hearing loss in drivers in Isfahan, Iran. Arch Iran Med 2009; 12(2):128-34.

28. Brant LJ, Gordon-Salant S, Pearson JD, Klein LL, Morrell CH, Metter EJ, et al. Risk factors related to age-associated hearing loss in the speech frequencies. J Am Acad Audiol 1996; 7(3):152-60.

29. Weisz N, Hartmann T, Dohrmann K, Schlee W, Norena A. High-frequency tinnitus without hearing loss does not mean absence of deafferentation. Hear Res 2006; 222(12):108-14.

30. Agrawal Y, Platz EA, Niparko JK. Prevalence of hearing loss and differences by demographic characteristics among US adults: data from the National Health and Nutrition Examination Survey, 1999-2004. Arch Intern Med 2008; 168(14):1522-30.

31. Shargorodsky J, Curhan SG, Curhan GC, Eavey R. Change in prevalence of hearing loss in US adolescents. JAMA 2010; 304(7):772-8.

32. Crocker MJ, Ivanov IN. Noise and vibration control in vehicles. $1^{\text {st }}$ ed. Petersburg, Russia: Interpublish Ltd; 1993.

33. Zulkarnain RZ, Nor MJM. Noise control using coconut coir fiber sound absorber with porous layer backing and perforated panel. Am J Appl Sci 2010; 7(2):260-4.

34. Saeki T, Fujii T, Yamaguchi S, Harima S. Effects of acoustical noise on annoyance, performance and fatigue during mental memory task. Appl Acoust 2004; 65(9):91321. 